\title{
Referenciação e ensino: panorama teórico e sugestões de abordagem de leitura
}

Leonor Werneck dos Santos ${ }^{a}$

Manuela Colamarco ${ }^{b}$

\begin{abstract}
Resumo
Neste artigo, traçamos um panorama teórico dos estudos de referenciação, considerado como um processo sociocognitivo de construção de sentidos, seguindo os estudos atuais de Linguística de Texto, conforme Mondada e Dubois (2003), Koch (2014), Cavalcante (2011), Cavalcante e Santos (2012), dentre outros autores. Visando a colaborar para o ensino de lingua portuguesa, sugerimos análises de dois gêneros textuais frequentemente abordados nos anos finais do ensino fundamental: fábula $e$ conto de terror. Nossa proposta de análise inclui sugestão de atividades que destacam as estratégias referenciais utilizadas nesses textos, considerandoas constitutivas dos gêneros em que ocorrem. Pretendemos demonstrar, com essa abordagem, como é possível articular pesquisas recentes em Linguística de Texto ao ensino de aspectos gramaticais e textuaisdiscursivos, como propõem os PCN.
\end{abstract}

Palavras-chave: Referenciação. Ensino de Lingua Portuguesa. Gêneros textuais.

Recebido em dezembro 2013. Aprovado em abril de 2014.

aUFRJ - Universidade Federal do Rio de Janeiro. Rio de Janeiro, Rio de Janeiro, BR. leonorwerneck@gmail.com bUFRJ - Universidade Federal do Rio de Janeiro. Rio de Janeiro, Rio de Janeiro, BR. manucolamarco@gmail.com 


\section{Introdução}

Nosso objetivo é apresentar aspectos associados aos processos referenciais, mostrando como eles podem colaborar para a leitura de textos literários - fábulas e contos de terror. Baseamo-nos na Linguística de Texto para conceituar texto e leitura - especificamente Koch (2003, 2014), Koch e Elias (2006, 2009), Marcuschi (2005, 2008), dentre outros. Além disso, discutiremos os processos referenciais, seguindo diferentes perspectivas teóricas, com base, principalmente, em Apothéloz (2001, 2003), Apothéloz e Reichler-Béguelin (1995), Conte (1996), Mondada e Dubois (2003), Cavalcante (2003, 2007, 2011), Koch; Morato; Bentes (2005), dentre outros.

Por questão de espaço, selecionamos para analisar textos predominantemente narrativos: duas fábulas (uma de Esopo e outra de Monteiro Lobato) e seis contos de terror. Com nossa análise, pretendemos mostrar a importância de relacionar os processos referenciais, presentes em qualquer texto, ao ensino de leitura e de língua portuguesa.

\section{Texto e referenciação numa perspectiva sociointeracional}

Segundo Koch \& Elias (2006), a Linguística de Texto tem se apoiado ultimamente em uma perspectiva sociocognitiva e interacional da linguagem, que parte do pressuposto de que as atividades de leitura e compreensão textuais dependem do acionamento de conhecimentos prévios, estando, portanto, ligadas a aspectos sociocognitivos. Nessa perspectiva, o texto é conceituado como um fenômeno comunicativo associado ao contexto sociocultural dos interlocutores (CAVALCANTE, 2011).

Nessa concepção, o texto é um processo em constante construção, uma materialização de determinado gênero - o que faz com que esteja submetido às regularidades linguísticas e temáticas desse gênero, conforme a situação enunciativa na qual circula. Dessa forma, a atividade de leitura depende de estratégias e de graus de percepção de aspectos inferenciais e referenciais, para não somente articular conhecimentos prévios como também colaborar com o levantamento de hipóteses. Por esse motivo, Marcuschi (2008, p. 72) alerta para a importância do objetivo dos interlocutores e do contexto sociocognitivo: "falamos 
de texto como um evento que atualiza sentidos e não como uma entidade que porta sentidos na independência de seus leitores".

Se consideramos, portanto, a construção de sentidos um processo colaborativo, decorrente do acionamento de conhecimentos prévios (conhecimentos de mundo, linguísticos, intertextuais, contextuais, interacionais), os processos referenciais também estão em permanente construção, já que os objetos-de-discurso não preexistem ao discurso, mas são ativados e reativados, interativa e discursivamente. Por isso, para Koch (2003, p. 30):

O sentido de um texto, qualquer que seja a situação comunicativa, não depende tão somente da estrutura textual em si mesma. Os objetos de discurso a que o texto faz referência são apresentados em grande parte de forma lacunar, permanecendo muita coisa implícita. O produtor do texto pressupõe da parte do leitor/ouvinte conhecimentos textuais, situacionais e enciclopédicos e, orientando-se pelo Princípio da Economia, não explicita as informações consideradas redundantes. Ou seja, visto que não existem textos totalmente explícitos, o produtor de um texto necessita proceder ao "balanceamento" do que necessita ser explicitado textualmente e do que pode permanecer implícito, por ser recuperável via inferenciação.

Esse pressuposto de que o texto deve ser concebido sob um caráter sociointeracional considera uma postura ativa do leitor, na busca por preencher as lacunas textuais, num cálculo mental de levantamento de hipóteses que depende do contexto sociocognitivo. Além disso, a concepção sociocognitiva e interacional da referenciação enfatiza a íntima relação entre coesão e coerência, que colaboram para o projeto de dizer e que precisam ser percebidas em conjunto.

O conceito de referenciação engloba formas de introdução de novos referentes e retomada, constituindo a progressão referencial. Os objetos de discurso são construídos na prática sociocognitiva, por isso a instabilidade dos referentes é inerente ao discurso, e o processo de construção/reconstrução dos objetos de discurso pressupõe uma interação entre os sujeitos do discurso, responsáveis por escolhas significativas para representar os referentes de acordo com a sua proposta de sentido. Só é possível identificar os objetos de discurso a partir de associações cognitivas, e os processos referenciais 
colaboram na construção dos efeitos de sentido das escolhas linguísticas no projeto de dizer. Por isso, é necessário fazer associações, conforme nossos conhecimentos prévios, para compreender as cadeias referenciais, e, conforme alertam Mondada \& Dubois (2003, p. 20), os objetos de discurso são analisados tendo em vista a coconstrução de sentido, por serem "objetos constitutivamente discursivos":

passando da referência à referenciação, vamos questionar os processos de discretização e de estabilização. Esta abordagem implica uma visão dinâmica que leva em conta não somente o sujeito "encarnado", mas ainda um sujeito sociocognitivo mediante uma relação indireta entre os discursos e o mundo. Este sujeito constrói o mundo ao curso do cumprimento de suas atividades sociais e o torna estável graças às categorias - notadamente às categorias manifestadas no discurso.

No que concerne às estratégias de referenciação, embora não seja nosso objetivo neste artigo polemizar a respeito de nomenclaturas e definições, é importante destacarmos alguns aspectos relevantes que vêm suscitando debates, conforme vemos em Santos e Cavalcante (2014). A rigor, os objetos de discurso introduzidos no texto são passíveis de serem retomados por uma estratégia anafórica retrospectiva ou prospectiva: havendo correferencialidade, trata-se de anáfora direta $(\mathrm{AD})$; não havendo, temos a anáfora indireta (AI). Segundo Conte (1996), há ainda um terceiro tipo, o encapsulamento, que estaria num meio-termo entre os dois tipos clássicos de anáfora, pois não é totalmente correferencial como a $\mathrm{AD}$, mas sumariza uma parte do texto e a ela se refere, necessitando de um certo grau de inferência para ser compreendida. Há, ainda, a dêixis, estratégia referencial comumente associada ao entorno sociocomunicacional, que toma o ponto de partida do falante (origo) para marcar, por exemplo, pessoa, espaço e tempo no discurso ${ }^{1}$.

Em relação aos processos referenciais supracitados, poderíamos nos perguntar em que consiste a correferencialidade. Depende do leitor ou é algo intrínseco ao texto? Segundo

${ }^{1}$ Esses casos referem-se à dêixis "pura" (cf. LYONS, 1978; LEVINSON, 1983), mas há outros casos de dêixis (de memória, social, textual), dos quais não trataremos neste artigo, por questão de espaço. Prince (1992), é necessário diferenciar o que é uma entidade nova para o texto de uma entidade nova para o ouvinte. Assim, o status de correferencialidade dependeria muito mais de uma construção de relações do que da percepção do leitor. $\mathrm{Na}$ análise das fábulas e dos contos de terror que propomos neste artigo, observamos que nem sempre a correferenciali- 
dade é óbvia, e muitas anáforas diretas, recategorizando o referente, constroem sentidos peculiares para os gêneros em que ocorrem.

Também podemos discutir a afirmação de que as AI não são correferenciais e necessitam de maior inferência, uma vez que a relação entre o objeto-de-discurso e a AI depende mais de conhecimentos compartilhados. Mas, como veremos em alguns exemplos, as $\mathrm{AD}$ também dependem de conhecimento prévio para serem compreendidas (cf. CIULLA E SILVA, 2008; MORAIS, 2012; CAVALCANTE eSANTOS, 2012, dentre outros) e, como dissemos acima, nem sempre a correferencialidade é facilmente percebida. Quanto ao encapsulamento, conforme observaremos em um dos contos de terror analisado, ao mesmo tempo em que não podemos dizer que ele é correferencial em relação à porção de texto à qual se refere, não podemos negar que há um certo grau de correferencialidade, uma vez que há retomada, não de um elemento do cotexto, mas de informações nele dispersas, recuperáveis pelo acionamento de conhecimentos prévios variados (cf. BORREGUERO, 2006).

Não pretendemos, neste artigo, nos aprofundar nesses aspectos polêmicos sobre referenciação, mas apenas ressaltar que, no momento atual em que se encontram os estudos sobre esse tema, há de se repensar os critérios de classificação.

\section{Refenciação e ensino}

Conforme postulam os Parâmetros Curriculares Nacionais, é necessário que o ensino de Língua Portuguesa esteja alicerçado em três práticas de análise distintas, porém complementares: a prática de leitura, de produção de textos e a reflexão sobre a língua. Nessa perspectiva, a observação dos aspectos linguísticos só se justifica se possibilitar a compreensão dos sentidos atribuídos a um texto e propiciar "a construção de um repertório de recursos linguísticos a ser utilizado na produção de textos" (BRASIL, 1997, p. 49).

Durante a leitura, para a compreensão do texto, é importante perceber a cadeia referencial construída. Segundo Koch e Elias (2006, p. 123), "eles (os referentes) são construídos e reconstruídos, de acordo com nossa percepção de mundo", isto é, não há uma perfeita equivalência entre as palavras e as coisas. 
Por isso, é necessário fazer associações, para compreender as cadeias referenciais.

Portanto, concordamos com Koch (2014, p. 35), que destaca que

O emprego de uma descrição nominal, com função de categorização ou recategorização de referentes, implica sempre uma multiplicidade de formas de caracterizar o referente(...). Trata-se, em geral, da ativação, dentre os conhecimentos culturalmente pressupostos como compartilhados, de características ou traços do referente que devem levar o interlocutor a construir dele determinada imagem(...) uma de suas funções textual-interativas específicas é a de imprimir aos enunciados em que se inserem, bem como ao texto como um todo, orientações argumentativas conformes à proposta enunciativa do seu interlocutor.

Os processos referenciais, segundo Cavalvante (2011), exercem duas grandes funções nos textos: (1) Introduzir um novo referente no universo discursivo; (2) Promover, por meio de expressões referenciais, a continuidade de referentes estabelecidos no universo discursivo. A percepção dessas funções é essencial para a compreensão da perspectiva argumentativa do texto, das intencionalidades, e pode ser trabalhada em sala de aula de várias maneiras.

Essa abordagem textual e discursiva, porém, nem sempre é feita nas escolas brasileiras, e diversas pesquisas apontam para a falta de uma abordagem coerente dos processos referenciais, tanto em livros didáticos quanto em análises de textos dos alunos (cf. TUPPER, 2013; GONÇALO, 2013). Nos livros didáticos brasileiros, ainda há uma abordagem superficial de mecanismos de progressão textual, muitas vezes há frases descontextualizadas para ilustrar recursos coesivos e presença de textos apenas para exemplificação, sem explorar como os elementos linguísticos aprendidos contribuem na construção de sentido desses textos; alguns livros, quando tratam dos processos referenciais, restringem-se à identificação dos referentes ou à eliminação de repetição, sem considerar aspectos textuais e discursivos envolvidos na construção e no processamento dos textos (SANTOS, 2013).

Acreditamos que a percepção da progressão referencial pode colaborar para o ensino de leitura e língua portuguesa, por isso propomos, a seguir, uma análise de duas fábulas e de 
alguns contos de terror, pensando em sugerir uma abordagem produtiva e crítica das estratégias referenciais em sala de aula. Quanto às fábulas, analisamos a cadeia referencial em versões de "A cigarra e a formiga", de Esopo e de Monteiro Lobato, mostrando como ela colabora para a arquitetura argumentativa do texto e para a construção dos objetos de discurso. Já no caso dos contos de terror, após analisarmos seis contos publicados no livro Frenesi (SEIXAS, 2006), destacamos dois deles e buscamos estabelecer uma metodologia de trabalho que levasse os alunos do $7^{\circ}$ ano do Ensino Fundamental a ler e a desenvolver sua escrita a partir da referenciação nesses textos.

\section{Análise contrastiva: "A cigarra e as formigas" de Esopo e de Monteiro Lobato}

Na abertura de seu livro Fábulas, Monteiro Lobato (LOBATO, 2008) recria o famoso texto de Esopo "A cigarra e as formigas" (ESOPO, 2002). Na fábula original, chegado o inverno, uma cigarra pede comida às formigas, pois, como não trabalhara no verão, não estava preparada para o tempo frio. As formigas, que passaram o verão inteiro trabalhando, negam ajuda à cigarra, que cantou durante toda a estação quente.

Na moral do texto de Esopo, lemos: “Esta fábula mostra que, em todo e qualquer assunto, ninguém deve ser negligente, a fim de não sofrer desgostos nem correr perigos". Finalmente, compreendemos que o não trabalhar (o cantar da cigarra) corresponde a uma negligência, ao passo que o trabalho configura a precaução. Assim, é transmitida para o leitor a lição de que não podemos nunca ser descuidados, ou seja, o texto ensina-nos que se não estivermos sempre preparados e atentos, passaremos por momentos difíceis.

No que diz respeito às estratégias de referenciação, no texto de Esopo, a expressão referencial "as formigas", presente no título da fábula, é repetida três vezes, sendo retomada, também, pelo pronome "lhes". Já o outro referente, introduzido, também no título da obra, como "a cigarra", é retomado por "uma cigarra com fome", modificando-se a forma definida pela indefinida e inserindo-se a expressão "com fome". Assim, não se observa, como ocorrerá no texto de Lobato, uma avaliação explícita de cada um dos animais pelo narrador, se avaliarmos apenas sua forma de denominação no texto. 
É interessante notar, no entanto, que os referentes introduzidos no título, "a cigarra" e "as formigas" são retomados, logo no início da narrativa, de modo diverso: a expressão "a cigarra" é recategorizada pelo anafórico direto "uma cigarra com fome", ao passo que a expressão referencial "as formigas" é repetida sem alteração formal. Assim, em "as formigas", utiliza-se o artigo definido, ao passo que em "uma cigarra com fome", a expressão indefinida acompanha o substantivo. Podemos entender, nessa estratégia, uma forma de sinalizar a maior importância das formigas em relação à cigarra, que seria, ao contrário das outras, "uma qualquer", uma vez que o artigo definido especifica o termo "formigas", enquanto o artigo indefinido atribui ao termo "cigarra" um caráter generalizante.

Na versão de Lobato, a fábula "A cigarra e as formigas" é dividida em dois momentos. No primeiro, "A formiga boa", a formiga abriga a cigarra em sua casa durante o inverno e garante o seu sustento; no segundo, "A formiga má", o desfecho da narrativa ocorre como na história original, com um agravante: a cigarra morre e, então, o verão seguinte torna-se triste, uma vez que não se escuta mais a sua música. Ou seja, embora o título de Lobato, "as formigas", esteja também no plural, ao contrário do que ocorre em Esopo, ele não se refere às formigas de maneira genérica, mas a duas formigas com comportamentos opostos: "a formiga boa" e "a formiga má", que participam, isoladamente, de cada um dos momentos do texto.

Logo no título "A formiga boa", percebemos uma avaliação positiva da primeira formiga em relação à segunda, "a formiga má", pelo narrador. Assim, já nessa primeira expressão anafórica ("a formiga boa" retoma, de certo modo, o referente "as formigas" presente no título da fábula), podemos observar uma atribuição de valor do narrador. Além disso, entendemos que, também nesse título, há um posicionamento crítico frente ao texto de Esopo, uma vez que, se essa formiga é a boa, e faz-se questão de explicitar isso, subentende-se que a outra, ou seja, a da fábula de Esopo, agiu errado, era a má. Confirma essa ideia o fato de a formiga da versão clássica ter o mesmo comportamento da formiga do segundo mom ento da fábula de Lobato, ou seja, ela age da mesma maneira que "a formiga má". "A formiga boa" é ainda recategorizada pela expressão "uma formiga friorenta embrulhada num xalinho de paina", em que o uso do diminutivo reforça a ideia de afetividade para com esse animal. 
A personagem cigarra, na fábula original, é caracterizada de forma bastante depreciativa, como alguém negligente, que deixou de trabalhar, que não se esforçou. Também essa ideia é desconstruída na fábula de Lobato, como comprovam as expressões referenciais utilizadas para nomear este segundo animal na progressão do texto, recategorizando "a cigarra":

Houve uma jovem cigarra que tinha o costume de chiar ao pé de um formigueiro. Mas o bom tempo afinal passou e vieram as chuvas. [...] A pobre cigarra, sem abrigo em seu galhinho seco e metida em grandes apuros, deliberou socorrer-se de alguém. (LOBATO, 2008, p.12; grifos nossos)

Aqui, a expressão "jovem cigarra que tinha o costume de chiar ao pé de um formigueiro" é retomada por meio do anafórico, "pobre cigarra, sem abrigo em seu galhinho seco e metida em grandes apuros", em que o substantivo é determinado pelo adjetivo "pobre", o que, dentro do contexto, evidencia uma avaliação positiva desse referente pelo narrador. O elemento referencial deixa subentendido, no texto, uma simpatia e uma cumplicidade para com essa personagem, intensificadas pela situação de penúria por que ela passa: "sem abrigo em seu galhinho seco e metida em grandes apuros". Vale lembrar que, se fosse outra a posição adotada na fábula em questão, adjetivos como "preguiçosa", "folgada" ou "esperta" poderiam aparecer no lugar de "pobre". Na continuação do texto, as expressões anafóricas "pobre cigarra, toda tremendo" e "triste mendiga suja de lama e a tossir" recategorizam "a cigarra", reforçando ainda mais sua angústia.

Mais adiante, lemos: "A cigarra entrou, sarou da tosse e voltou a ser a alegre cantora dos dias de sol" (LOBATO, 2008, p.12; grifo nosso). Nesse trecho final da fábula, o termo "jovem cigarra" é retomado por meio da expressão anafórica "alegre cantora dos dias de sol", o que evidencia novamente para o leitor uma avaliação positiva do referente cigarra: ela é uma artista e, além disso, é enaltecida com o adjetivo "alegre". Ainda, compreendemos que seu cantar corresponde a um trabalho, já que ela é nomeada como cantora.

Na segunda parte da fábula, como vimos, a expressão "a formiga má" retoma, novamente, a expressão "as formigas" do título do texto. Na progressão do texto, esse referente vai ser recuperado, em alguns trechos, pelo anafórico "formiga" 
e, em outros momentos, ao ser retomado, receberá, ainda, novas configurações, pois será recategorizado pelas expressões anafóricas "uma formiga má que não soube compreender a cigarra", "uma usurária sem entranhas" e "a usurária". Nesses últimos casos, é evidente a avaliação depreciativa feita do animal, que não acolheu a cigarra em sua casa no inverno. Além disso, a primeira expressão anafórica recategorizadora evidencia o caráter intolerante/ intransigente do referente formiga, que não soube compreender o outro animal. É ainda interessante notar que a formiga má também é carcterizada como "invejosa", o que introduz uma ideia nova no texto, que não aparecia na fábula de Esopo. Nesta nova versão da fábula, um dos motivos pelos quais a formiga não abrigou a cigarra em sua casa é a inveja, conforme se lê mais adiante: "Como não soubesse cantar, tinha ódio à cigarra por vê-la querida de todos os seres" (LOBATO, 2008, p.13).

Observemos, logo abaixo, dois trechos da fábula de Lobato, o primeiro retirado de "A formiga boa" e, o segundo, de "A formiga má". Neles, há o relato do momento em que a cigarra vai até a casa da formiga pedir ajuda.

A pobre cigarra sem abrigo em seu galhinho seco e metida em grandes apuros, deliberou socorrer-se de alguém.

Manquitolando, com uma asa a arrastar, lá se dirigiu para o formigueiro. Bateu - tique, tique, tique...

[...]

- Venho em busca de agasalho. O mau tempo não cessa e eu... (LOBATO, 2008, p.12; "A formiga boa")

Desesperada, [a cigarra] bateu à porta da formiga e implorou - emprestado, notem! - uns miseráveis restos de comida. Pagaria com juros altos aquela comida de empréstimo, logo que o tempo permitisse. (LOBATO, 2008, p.13; “A formiga má”)

Comparando os dois trechos, percebemos que o segundo relato é bem mais carregado de emoções, enfatizando a situação de angústia e desespero por que passava a cigarra. Evidenciam isso as observações listadas a seguir, relacionadas às estratégias referenciais:

(i) No segundo trecho transcrito, a cigarra implora por "miseráveis restos de comida". Essa expressão se opõe ao termo 
"agasalho", utilizado no primeiro excerto para determinar o pedido do animal, ressaltando, assim, sua situação de pobreza extrema no segundo momento.

(ii) A expressão citada no item anterior "miseráveis restos de comida" introduz um novo referente no texto, que será retomado pelo anafórico recategorizador "aquela comida de empréstimo". Com isso, entende-se que aquele resto de comida que, na concepção de muitos, deveria até mesmo ser jogado fora, será aceito pela cigarra como o seu alimento do inverno. Além disso, reafirma-se a ideia de que a cigarra não quer ganhar nada de graça, mas está apenas pedido um empréstimo à usurária formiga.

Ainda nesta segunda parte da fábula, lemos: "Resultado: a cigarra ali morreu entanguidinha". (LOBATO, 2008, p.13; grifo nosso). Desse modo, vemos que o resultado do egó́smo da formiga foi o fim trágico da cigarra, que morreu inteiriçada com frio. Rassaltamos que a opção por utilizar o adjetivo "entanguido" no grau diminutivo, transmite uma ideia de afetividade e reafirma, com isso, uma cumplicidade para com a cigarra.

Na moral da fábula "A cigarra e as formigas" de Monteiro Lobato afirma-se: "Os artistas - poetas, pintores, músicos - são as cigarras da humanidade" (LOBATO, 2008, p.13; grifo nosso). Avaliando as estratégias de referenciação, podemos dizer que, aqui, por meio de uma contrução que conta com o auxílio de um verbo de ligação, é estabelecida uma relação de equivalência entre os artistas e a cigarra. Assim, por meio de uma anáfora direta, a expressão referencial "os artistas", introduzida ao final do texto, é retomada e recategorizada por "as cigarras da humanidade". Constrói-se, desse modo, uma metáfora, figura de linguagem que, consoante Fiorin, "[...] despreza uma série de traços e leva em conta apenas alguns traços comuns a dois significados que coexistem. Com isso, dá concretude a uma ideia abstrata, aumentando a intensidade do sentido." (FIORIN, 2014, p.34; grifos nossos).

Ou seja, dessa metáfora, entendemos, finalmente, que, assim como a cigarra da fábula, os artistas não são compreendidos e acabam sendo vítimas de injustiças. Desse modo, introduz-se uma discussão inesperada no contexto, que vai muito além do que era observado em "A cigarra e a formiga" de Esopo. Também notamos, no texto da moral, o uso do verbo no presente do indicativo, o que reforça a atualidade da assertiva. 
Além disso, ao contrário do que se postula como prototípico do gênero fábula, a moral de "A cigarra e as formigas" de Lobato não traz um ensinamento sobre o correto comportamento do ser humando, como ocorre no texto de Esopo, cuja moral nos exorta a não sermos negligentes. Em Lobato, a moral faz uma denúncia. Assim, entendendo que a moralidade pode determinar a interpretação da narrativa, compreendemos que a parte destinada à "formiga má", manifesta a situação de injustiça por que passam os artistas, que não têm, como a cigarra, seu trabalho reconhecido como tal.

A análise aqui desenvolvida pode ser transposta para a sala de aula do Ensino Básico de diversas maneiras. Vale ressaltar que as fábulas, comumente, são objeto de estudo do $6^{\circ}$ ano do Ensino Fundamental. Apenas a título de exemplificação, propomos as seguintes questões de análise textual, que levam o aluno a perceber como se constrói, nos textos, o objeto de discurso cigarra, e como ele é avaliado pelos narradores. Simples atividades como essas associam as práticas de leitura e de análise linguística, estimulando, ainda, a leitura crítica do aluno, mesmo de textos narrativos (cf. COLAMARCO, 2014):

1) Complete o quadro com as expressões utilizadas pelos narradores dos dois textos para se referir à cigarra. (junto à questão deve vir um quadro para ser completado)

2) Observando somente os termos transcritos no quadro, é possível identificar como o narrador de cada uma das fábulas avalia a cigarra? Justifique.

3) Avaliando, novamente, o quadro anterior, caracterize a cigarra de Monteiro Lobato. Você pode desenhar como imagina essa cigarra. (a mesma questão pode ser proposta para a cigarra de Esopo)

\section{Narrativas de terror em sala de aula: unindo teoria e prática}

Em Frenesi - Histórias de duplo terror, Heloísa Seixas cria seis contos de terror que dialogam com outros textos desse gênero, reconhecidos universalmente. Esse livro foi trabalhado em sala de aula, em uma turma de $7^{\circ}$ ano do Ensino Fundamental. Assim, a proposta de abordagem desses contos, apresentada de forma resumida a seguir, tem como principal objetivo aprimorar a escrita dos alunos por meio da análise das estratégias referenciais constitutivas dos contos de terror. 
Para tanto, analisamos os seis contos do livro visando observar como as estratégias de referenciação colaboram na construção do mistério que caracteriza esse gênero textual. Em sala de aula, seguimos as seguintes etapas: após a análise das estratégias de referenciação características das narrativas de terror, desenvolvemos, para os mesmos contos, exercícios de análise linguística/ textual, com o objetivo de levar aos estudantes as evidências observadas. Por fim, os alunos foram convidados a produzir as suas próprias narrativas de terror.

Um recurso bastante recorrente nos textos avaliados é a utilização de pronomes na introdução do referente, que, somente na continuação do texto, é identificado por meio de uma expressão anafórica, conforme se pode observar no trecho abaixo, retirado do primeiro parágrafo do conto "A Ilha":

Não havia qualquer pressentimento na ar quando eles desembarcaram. [...] a ilha os envolveu de imediato [...] e os jovens - três rapazes, duas moças - pularam do barco com cuidado [...]. (SEIXAS, 2006, p. 9; grifos nossos)

Ainda, no trecho a seguir, também transcrito do parágrafo inicial de um dos contos do livro, "Frenesi", o pronome indefinido sublinhado faz referência não a um referente específico que será apresentado na continuação do texto, mas a toda uma ação relatada, posteriormente, na narrativa: a suposta perseguição de um mascarado à personagem Cecília em pleno carnaval carioca. Esse pronome funciona, portanto, como um elemento encapsulador, já que resume toda uma parte do texto. Seu sentido indefinido, por isso, bastante vago, possibilita o suspense, pois leva o leitor a se perguntar o que será esse "tudo" que aconteceu.

Há dias que nos trazem um presságio, dias em que um pequeno incidente ou a visão de alguma coisa carregam a mensagem do que vai ocorrer mais tarde [...] Foi assim no dia em que tudo aconteceu. (SEIXAS, 2006, p. 93; grifos nossos)

Nos manuais de redação e também nos livros didáticos de Língua Portuguesa, é comum que se apresente como verdade absoluta a ideia de que a repetição de palavras é um mal a ser evitado, com vistas à produção de um texto mais elegante. Essa generalização parece esquecer que há casos em que essa repetição é legítima e, até mesmo, importante (cf. TUPPER, 
2013). Nas narrativas de terror, por exemplo, observamos que a repetição de um mesmo referente, enfatizando determinada ideia, é um recurso bastante explorado na construção do mistério. No fragmento transcrito acima, o substantivo "dias" foi repetido duas vezes em um mesmo período, assim como a expressão referencial "alguma coisa" em "[...] Daniel pensou ter visto alguma coisa faiscar em sua mão, alguma coisa que brilhou na luz mortiça do crepúsculo" (SEIXAS, 2006, p. 17; grifos nossos).

Finalmente, o suspense dos contos de terror é também garantido por meio da utilização de expressões referenciais de sentido vago ou de pronomes que não são retomados na progressão do texto, ou seja, o leitor chega ao final da narrativa sem conseguir construir, em sua mente, o objeto de discurso de maneira precisa.

No Quadro 1, os quatro recursos encontrados nos textos da Heloísa Seixas podem ser observados de forma mais esquemática. Ainda, na coluna ao lado, transcreveram-se alguns exercícios elaborados com vistas a traduzir, para os alunos, as descobertas feitas. 


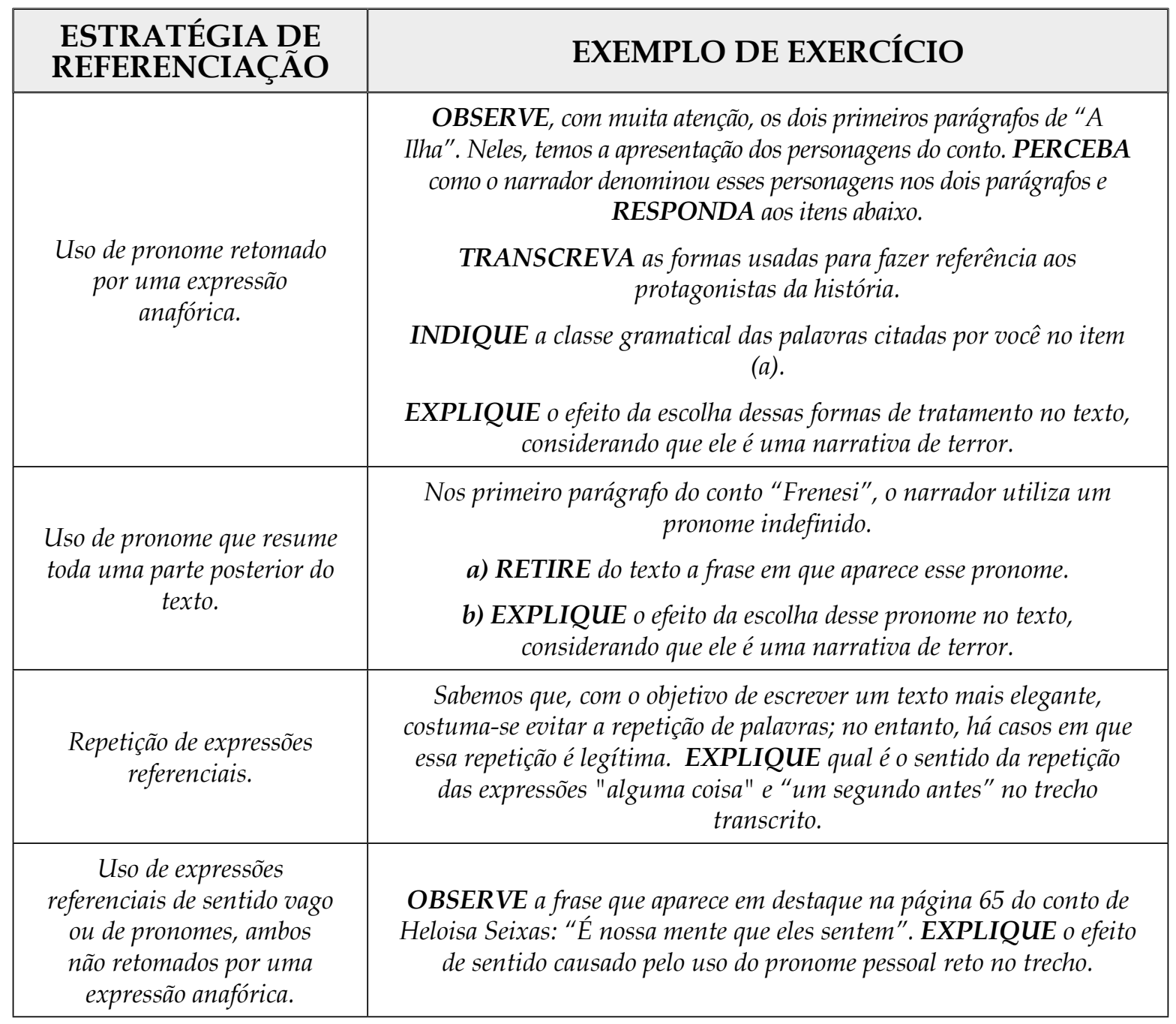

Quadro 1: Estratégias de referenciação características das narrativas de terror e exercícios elaborados a partir de sua observação.

Ao produzirem suas próprias narrativas de terror, após responderem aos exercícios de análise dos textos, também corrigidos e comentados em sala de aula, os alunos conseguiram fazer uso das estratégias de referenciação características do gênero textual em suas produções, como comprova o trecho a seguir. Nele, um aluno do $7^{\circ}$ ano do Ensino Fundamental apresenta seus personagens por meio de um pronome que, depois, é retomado pelos substantivos próprios que nomeiam cada um dos personagens da narrativa de terror. 
No interior do Tennesse, existia uma casa abandonada. Ao seu redor, um enorme campo. Vazio. Como se houvesse sido evacuado há tempos e ninguém ainda pensasse em visitá-lo.

Eles resolveram acampar. No dia 31 de outubro, noite de Halloween. Eles eram cinco no total, todos jovens: Elisa, Alice, Jack, Thomas e Kenji.

Desse modo, percebemos que, se forem estimulados a observar a cadeia referencial nos textos, os alunos conseguem perceber os mecanismos linguísticos utilizados na construção dos textos e utilizá-los, eles mesmos, em suas produções.

\section{Conclusão}

A relação entre coesão e coerência depende de um contexto sociocultural, mas o leitor menos proficiente nem sempre consegue construir sentidos dos textos a que tem acesso na escola e na vida cotidiana. Por isso, é necessário que na escola mostremos como se constrói a cadeia referencial, afinal, conforme alertam Santos, Cuba Riche e Teixeira (2012, p. 20),

não basta identificar a que elemento no texto determinado pronome ou substantivo se refere, porque, muitas vezes, há mais de um elemento morfossintaticamente capaz de associar-se a esses termos. Para compreender um texto, é necessário relacionar os elementos de retomada à construção de seu sentido.

Fazendo um breve panorama do ensino de língua portuguesa no Brasil, podemos afirmar que, apesar das reformulações, nos últimos 20 anos, o texto muitas vezes continua sendo tratado como produto, e temas como coesão, coerência, intencionalidade, começaram a ser discutidos em sala e a aparecer em livros didáticos, sem que os professores percebessem a importância devida a esses aspectos de textualidade (cf. ANTUNES, 2009; SANTOS, 2011). Tem havido grande incentivo à formação e atualização docente, à avaliação de material didático, mas ainda não é realidade em todas as escolas o trabalho com texto, como unidade de ensino.

Quando se toma o texto como unidade de ensino, é necessário analisá-lo em seu conjunto, observando as especifici- 
dades dos gêneros e suas regularidades linguísticas. Essa busca pela interação texto-linguagem ainda não foi feita plenamente no ensino de língua portuguesa no Brasil, ainda que seja comum ouvirmos que um dos objetivos do ensino de língua é formar leitores e desenvolver o potencial crítico do aluno.

No decorrer deste artigo, discutimos a relação entre os processos referenciais e o ensino de leitura. Se consideramos atualmente que a referenciação é uma prática discursiva, marcada por estratégias sociocognitivas e interacionais, é importante destacar na escola o papel do leitor na construção de sentidos do texto. A percepção dos processos referenciais depende de diversos fatores (CAVALCANTE ESANTOS, 2012), que podem colaborar para identificar os objetos de discurso retomados pelas anáforas, auxiliando na percepção da progressão referencial.

Ainda há muito a discutir em relação a conceitos teóricos relacionados à referenciação, mas é cada vez mais urgente inserir a análise dos processos referenciais no ensino para colaborar na formação do leitor crítico, que pode vir a produzir textos também com mais consciência das potencialidades textuais e discursivas de que pode dispor. Por exemplo, usando estratégias de referenciação que constituam elementos basilares na construção do mistério, característica fundamental dos contos de terror. E, finalmente, é necessário levar até os alunos as descobertas do meio acadêmico por meio de metodologias e materiais a serem desenvolvidos.

\section{REFERÊNCIAS}

ANTUNES, Irandé. Lingua, texto e ensino. São Paulo: Parábola, 2009. APOTHELOZ, D. Référer sans expression référentielle: gestion de la référence et opérations de reformulation dans des séquences métalinguistiques produites dans une tâche de rédaction conversationnelle. In: ENIKÖ, N. (Ed.). Pragmatics in 2000: selected papers from the 7th International Pragmatics Conference. v. 2. Antwerp: International Pragmatics Association, 2001. p. 30-38.

APOTHELOZ, D. Papel e funcionamento da anáfora na dinâmica textual. In: CAVALCANTE, M. M., RODRIGUES, B. B., CIULLA, A. (Org.). Referenciação. São Paulo: Contexto, 2003. p. 52-84. 
APOTHELOZ, D. \& REICHLER-BEGUELIN, M.-J. Construction de la référence et stratégies de désignation. In: BERRENDONNER, A. \& REICHLER-BEGUELIN, M-J. (Ed.). Du syntagme nominal aux objets-de-discours: SN complexes, nominalizations, anaphores. Neuchâtel: Institute de linguistique de l'Université de Neuchâtel, 1995. p. 227-271.

BORREGUERO, M. Naturaleza y función de los encapsuladores en los textos informativamente densos (la noticia periodística). Cuadernos de Filología Italiana, 13, p. 73-95, 2006.

BRASIL. Secretaria de Educação Fundamental. Parâmetros curriculares nacionais: língua portuguesa.v. 2 Brasília, DF. 1997.

CAVALCANTE, M. et al. (Org.). Referenciação. São Paulo: Contexto, 2003.

CAVALCANTE, M.. (Org.). Texto e discurso sob múltiplos olhares: referenciação. Rio de Janeiro: Lucerna, 2007.

CAVALCANTE, M. Referenciação: sobre coisas ditas e não ditas. Fortaleza: UFC, 2011.

CAVALCANTE, M. \& SANTOS, L. W. dos. Referenciação e marcas de conhecimento compartilhado. Lingua(gem) em Discurso, v. 12, n. 3, p. 657-681, 2012.

CIULLA e SILVA, A. Os processos de referência e suas funções discursivas: o universo literário dos contos. Tese (Doutorado em Linguística) - Universidade Federal do Ceará, Fortaleza, 2008.

COLAMARCO, M. Referenciação e ensino: abordagem comparativa de fábulas. 2014 [no prelo].

CONTE, M. Anaphoric Encapsulation. Belgian Journal of linguistics, 10, 1-10. 2006.

ESOPO. As fábulas de Esopo: em texto bilingue grego português. Rio de Janeiro: Thex Ed, 2002.

FIORIN, J. L. Figuras de retórica. São Paulo: Contexto, 2014.

GONÇALO, Fabiana da C. Referenciação em atividades de leitura com crônicas: uma análise dos livros didáticos de português. Dissertação (Mestrado em Língua Portuguesa) - Universidade Federal do Rio de Janeiro, Rio de Janeiro, 2013.

KOCH, I. Desvendando os segredos do texto. São Paulo: Cortez, 2003. 
KOCH, I. As tramas do texto. Rio de Janeiro: Contexto, 2014.

KOCH, I. \& ELIAS, V. Ler e compreender: os sentidos do texto. São Paulo: Contexto, 2006.

KOCH, I. \& ELIAS, V. Ler e escrever: estratégias de produção textual. São Paulo: Contexto, 2009.

KOCH, I., MORATO, E.M., BENTES, A.C. (Orgs.). Referenciação e Discurso. São Paulo: Contexto, 2005.

LEVINSON, S. Pragmatics. Cambridge: Cambridge University Press, 1983.

LOBATO, M. Fábulas. São Paulo: Globo, 2008.

LYONS, J. Semantics. Cambridge: Cambridge University Press, 1978.

MARCUSCHI, L.A. Anáfora indireta: o barco textual e suas âncoras. In: KOCH, I., MORATO, E., BENTES, A. C. (Orgs.). Referenciação e discurso. São Paulo: Contexto, 2005. p. 53-102.

MARCUSCHI, L.A. Produção textual, análise de gêneros e compreensão. São Paulo: Parábola, 2008.

MONDADA, L. \& DUBOIS, D. Construção dos objetos de discurso e categorização: uma abordagem dos processos de referenciação. In: CAVALCANTE, M. M., RODRIGUES, B. B., CIULLA, A. (Orgs.). Referenciação. São Paulo: Contexto, 2003. p. 17-52.

MORAIS, M. Processos de referenciação nos relatos esportivos. Dissertação (Mestrado em Língua Portuguesa) - Universidade Federal do Rio de Janeiro, Rio de Janeiro, 2012.

PRINCE, E. Towards a taxonomy of given-new information. In: COLE, P. (Ed.). Radical Pragmatics. New York: Academic Press, 1982. p. 223-255.

SANTOS, L. W. (org.). Gêneros Textuais nos Livros Didáticos de Português: uma análise de manuais do ensino fundamental. Rio de Janeiro: UFRJ, 2011.

SANTOS, L.W. Referenciação e Ensino: análise de livros didáticos. Rio de Janeiro: UFRJ, 2013.

SANTOS, L.W.; CAVALCANTE, M. Processos de referenciação: revisando conceitos. 2014 [no prelo]. 
SANTOS, L. W. dos, RICHE, R. C., TEIXEIRA, C. Análise e produção de textos. São Paulo: Contexto, 2012.

SEIXAS, H. Frenesi - histórias de duplo terror. Rio de Janeiro: ROCCO, 2006.

TUPPER, Letícia de L. A referenciação nos livros didáticos de Ensino Médio. Dissertação (Mestrado em Língua Portuguesa) - Universidade Federal do Rio de Janeiro, Rio de Janeiro, 2013.

\section{Abstract \\ Referencing and teaching: theoretical panorama and suggestions for reading approach}

In this article, we will present $a$ theoretical overview about of studies on referencing, regarded as a socialcognitive process of construction of senses, according to the current studies of Text Linguistics as Mondada and Dubois (2003), Koch (2014), Cavalcante (2011), Cavalcante and Santos (2012), among other authors. In order to contribute to Portuguese language teaching, we will suggest two analyses of textual genres often studied in final years of the elementary school: fable and horror tale. Our proposal of analysis includes suggestions of activities that highlight the referential strategies used in these texts, considering them constitutive of the genres in which they occur. We intend to demonstrate, with this approach, that it is possible to articulate recent research in Text Linguistics to the teaching of grammatical and textual-discursive aspects, as proposed by the national curriculum parameters (PCN).

Keywords: Referencing. Language teaching. Textual genres. 